\title{
Effect of Interprofessional Clinical Debates on Attitudes of Interprofessional Teams
}

Taylor D. Steuber, PharmD, BCPS | Miranda R. Andrus, PharmD, BCPS, FCCP | Bradley M. Wright, PharmD, BCPS, FASHP | Nancy Blevins, MD | Haley M. Phillippe, PharmD, BCPS, BCGP, FASCP

PRiMER. 2021;5:14.

Published: 4/7/2021 | DOI: 10.22454/PRiMER.2021.154149

\section{Abstract}

Introduction: Current evidence supports the notion of debates as a pedagogical method to teach literature evaluation skills in health care education; however, there are no reports of this method as an interprofessional approach and its potential benefits. The aim of this study was to assess the impact of interprofessional clinical debates on attitudes toward interprofessional teamwork and perceived literature evaluation skills.

Methods: We invited third-year family medicine residents and fourth-year pharmacy students to complete a survey before and after participating in an interprofessional clinical debate. The anonymous survey was composed of the Students' Perceptions of Interprofessional Clinical Education-Revised (SPICE-R2) instrument to evaluate perceptions of interprofessional teamwork, literature evaluation, and other skills gained through the process. We evaluated matched responses for change in attitudes toward interprofessional teams.

Results: We evaluated 41 matched responses, which indicated improvement in attitudes toward interprofessional teams and was statistically significant $(P<.001)$. This finding held true for subscales of roles/responsibilities for collaborative practice and patient outcomes from collaborative practice $(P<.001)$. Participants also perceived improvements in literature evaluation, problem-solving, critical thinking, teamwork, and communication skills.

Conclusion: The interprofessional clinical debate activity positively impacted medical residents and pharmacy students, and improved attitudes toward interprofessional teams.

\section{Introduction}

Debates are a pedagogical alternative to traditional journal clubs for literature evaluation in health professions education. They have been used in multiple silos of health care education at a variety of learner levels. ${ }^{1-21}$ Debates can introduce complex and controversial issues and improve clinical knowledge acquisition, communication, critical thinking, and teamwork. ${ }^{2}$ Interprofessional education (IPE) is a vital component of health care education to "prepare future health professionals for enhanced team-based care of patients and improved population health outcomes." 22 To improve education surrounding literature evaluation and expand 
IPE, a family medicine residency program and school of pharmacy collaborated to develop and implement interprofessional clinical debates (ICDs). The goal of this activity was for postgraduate year-3 family medicine residents (PGY-3s) and fourth-year pharmacy students (P4s) to collaborate in literature evaluation and provide an engaging alternative to journal clubs. Despite the reported effectiveness of debates in individual health care education disciplines, little information exists regarding an interprofessional approach to debates. The objective of this study was to assess the impact of ICDs on attitudes toward interprofessional teams.

\section{Methods}

The Auburn University Institutional Review Board deemed this project exempt from review as an anonymous educational survey conducted in an established educational setting. Participants were PGY-3s and P4s who participated in ICDs from August 2017 to April 2019. Teams consisted of two to four P4s and one PGY-3. Team roles included lead debater to present the opening argument, rebutter(s) to ask and answer questions, and closer to present the concluding statements.

ICD topics were controversial clinical questions with two competing viewpoints, the absence of a clear right answer, and evidence supporting both sides (Table 1). These were scheduled monthly during spring and fall. Teams were evaluated with a rubric based on course requirements on their opening argument, questions, rebuttal, and closing arguments, as well as presentation style, persuasiveness, ability to answer questions, written summary, and bibliography. The ICD format is represented in Figure 1.

We administered electronic presurveys at the beginning of the 2017 and 2018 academic years. Presurveys included demographics and the Student Perceptions of Interprofessional Clinical Education-Revised instrument (SPICE-R2) to measure attitudes toward interprofessional teams and care. ${ }^{24}$ The 10 -item survey is on a 5-point Likert scale from $1=$ strongly disagree to $5=$ strongly agree. It includes three subscales: Interprofessional Teamwork and Team-based Practice (T-subscale, 4 items), Roles/responsibilities for Collaborative Practice (R-subscale, 3 items), and Patient Outcomes from Collaborative Practice (0-subscale, 3 items). We selected the SPICE-R2 because it fit study objectives, is concise, has demonstrated reliability, and can evaluate IPE perceptions from a pre/postperspective. Following ICD participation, we administered postsurveys, which included the SPICE-R2 and author-generated questions related to perceived literature evaluation, problem-solving, critical thinking, teamwork and communication skills, and preferences for ICDs versus journal clubs. These questions were adapted from published literature on clinical debate perceptions in pharmacy students. ${ }^{11}$

We included matched responses in the final analysis. We evaluated baseline characteristics and skills perceptions by descriptive statistics. We established reliability for the SPICE-R2. The Cronbach a for the overall instrument was good (0.89) and ranged from acceptable to good for each subscale (0.79 to 0.85 ), indicating adequate internal consistency. This was similar to or slightly higher than the reliability of the overall instrument (0.79) and subscales (0.68 to 0.85 ) established with the validation of the instrument. ${ }^{24}$ We tested responses on the SPICE-R2 for normality with the Shapiro-Wilk test, revealing nonnormal distribution. We analyzed changes in matched responses on the SPICE-R2, including subscales, with the Wilcoxon Signed-Rank Test. We conducted subgroup analyses for PGY-3s and P4s. We considered $P$ values $<.05$ to be statistically significant. We conducted statistical analyses using SPSS v25.0 (Armonk, NY).

\section{Results}

Over 2 years, 65 learners participated in 11 ICDs, including 22 PGY-3s and 43 P4s. Forty-one participants responded to both the pre- and postsurveys (response rate 63\%), including 10 PGY-3s (24.4\%) and 31 P4s (75.6\%). Twenty-five were female (61\%), and the average age was $27 \pm 3.4$ years. At baseline, participants had 
positive attitudes toward interprofessional teamwork with median responses of "agree" or "strongly agree" on summative and subscale scores on the SPICE-R2.

Results of the SPICE-R2 are displayed in (Table 2). There was significant improvement in overall SPICE-R2 scores from the presurvey to postsurvey $(P<.001)$. There were significant improvements in R-subscale and O-subscale scores $(P<.001)$, but not T-subscale scores $(P=.052)$. When analyzing subgroups, there were significant increases in overall SPICE-R2 scores $(P<.05)$. Results of the skills perceptions survey are displayed in (Table 3). Overall, learners felt ICDs improved their ability to analyze clinical literature and/or work in interprofessional teams; however, they were neutral in their preference of ICD over journal clubs.

\section{Discussion}

ICDs were an engaging activity that demonstrated modest, but statistically significant improvements in attitudes toward interprofessional teams in both PGY-3s and P4s. These findings were despite baseline positive attitudes, and was likely influenced by the process of meeting multiple times during the 5-week period to research and develop their arguments. This provided opportunities to discuss their background and education, roles within health care teams, and develop a well-thought-out therapeutic plan as a team to defend their stance during the debate. This likely influenced improvements in overall SPICE-R2 scores and the R- and O-subscales. We did not see a significant improvement in the T-subscale, likely because of high baseline scores. In addition, most participants thought ICDs were educationally valuable as they perceived a positive impact on their literature evaluation, problem-solving, critical thinking, teamwork, and communication skills. To our knowledge, this is the first study of its kind to include an interprofessional approach to debates in health care education.

Most matched surveys were represented by P4s; however, this was representative of overall participation in the ICD activity. Subgroup analyses indicated results were consistent for both groups. Furthermore, the sample transverses 2 years, which improves generalizability. Variable experiences during their training may have impacted survey results; however, the postsurvey was administered immediately after the debate to focus on this activity. Other factors potentially influencing survey results included time during the academic year, baseline ability to evaluate literature, public speaking comfort level, and differences in team dynamics and personalities.

Despite ICD's perceived benefit, approximately one-third of P4s indicated they preferred traditional journal clubs, one-third indicated no preference, and one-third indicated they preferred ICDs. This sharply contrasted with PGY-3s, who mostly preferred ICDs. This may be explained by the large time commitment for preparing a debate or fear of presenting to large groups, both of which PGY-3s may be more accustomed to. Furthermore, the team roles taken may have influenced learners' preference of ICD compared to journal clubs. For example, $\mathrm{P} 4 \mathrm{~s}$ often took the role of rebutter, a difficult role which requires more improvisation and ability to think on their feet. Depending on their experience, this may have influenced their perception of ICDs. Additionally, P4s worked toward a numeric grade, whereas PGY-3s were only required to pass the assignment.

Other potential limitations exist. First, the SPICE-R2 tool was generated primarily for early learners. ${ }^{24}$ Additionally, the survey consists of all positive statements, introducing potential for response bias. Despite these limitations, our survey results demonstrated good internal consistency, and observed changes, although modest, were similar to previous studies. ${ }^{25-28}$ Furthermore, this reflects one activity and could be used in conjunction with other IPE activities to improve learners' interprofessional teamwork perceptions. Finally, the postsurvey perception questions were not validated prior to administration. However, these questions were adapted from prior literature and were only meant to identify trends. In sum, these findings echo results from other studies in health care education debates, demonstrating effectiveness in developing communication, 


\section{Conclusions}

Overall, learners who participated in ICDs reported improved attitudes toward interprofessional teams after the activity. Although there are challenges to implementing ICDs, the results demonstrate ICDs are effective.

\section{Tables and Figures}

\section{Table 1: Interprofessional Clinical Debate Topics}

- SGLT-2 inhibitors versus GLP-1 agonists as second-line to metformin in type 2 diabetes for prevention of cardiovascular outcomes

- Apixaban versus warfarin for stroke reduction in nonvalvular atrial fibrillation

- Eplerenone versus spironolactone for mortality reduction in HFrEF

- Ticagrelor versus clopidogrel for dual antiplatelet therapy following acute coronary syndromes

- GLP-1 agonists versus rapid acting insulin as add-on to long-acting insulin therapy

- Statin use in the very elderly population for primary prevention (in favor versus against)

- Metoprolol succinate versus carvedilol for morality reduction in HFrEF

- Clopidogrel versus aspirin/dipyridamole for secondary ischemic stroke prevention

- ARNi versus ACE-I for mortality reduction in HFrEF

- Extended dual antiplatelet therapy beyond 12 months after coronary stenting (in favor versus against)

- Evolocumab for reduction of cardiovascular events (posed as a formulary question, in favor or against adding to formulary)

Abbreviations: SGLT-2, Sodium-glucose cotransporter-2; GLP-1, glucagon-like peptide 1; HfrEF, heart failure with reduced ejection fraction; ARNi, angiontensin receptor neprilysin inhibitor; ACE, angiotensin-converting enzyme.

Figure 1: Interprofessional Clinical Debate Process and Structure

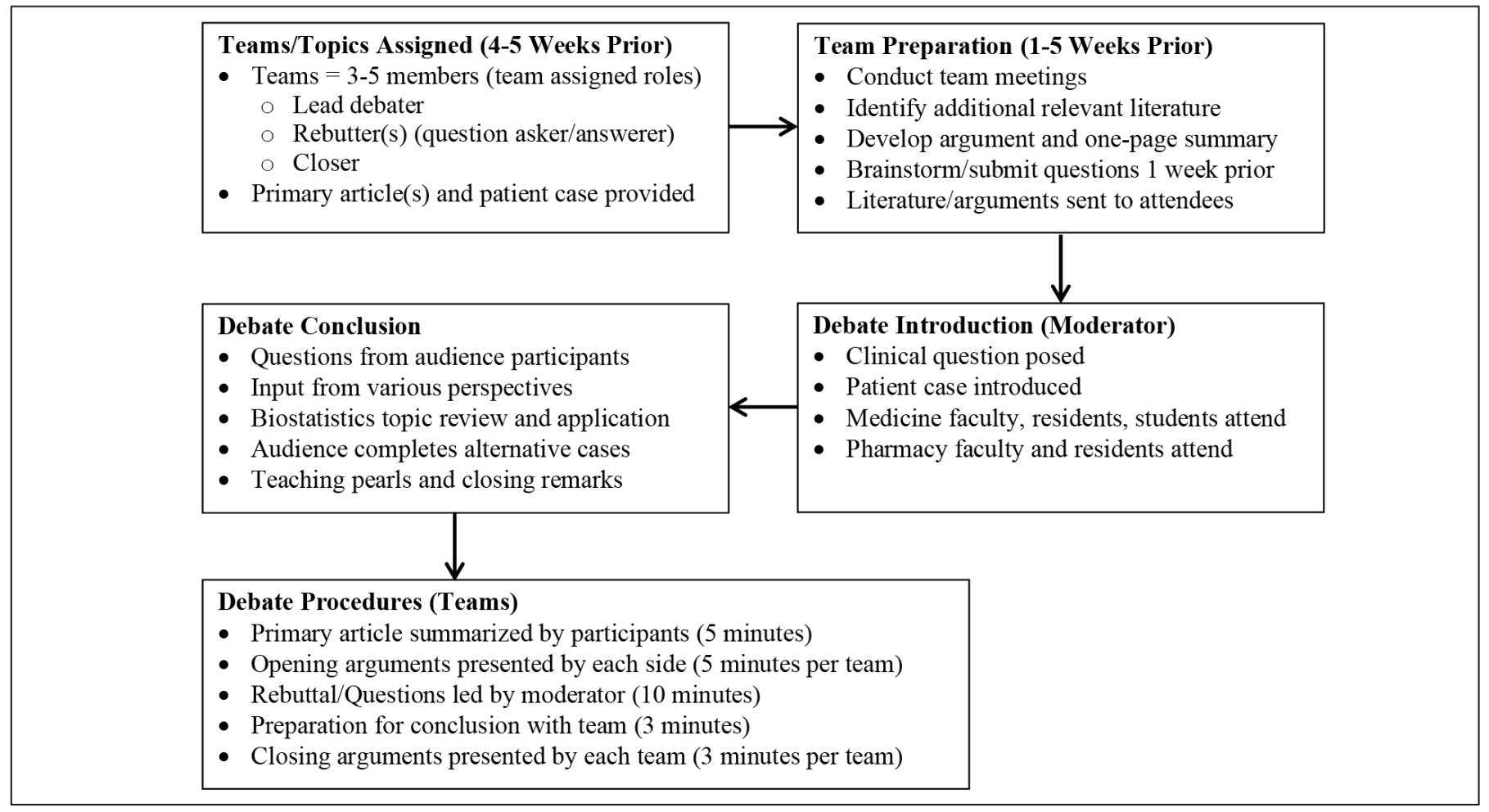


Table 2: Changes in Attitudes Towards Interprofessional Teams Measured via the SPICE-R2 Instrument ${ }^{\mathrm{a}}$

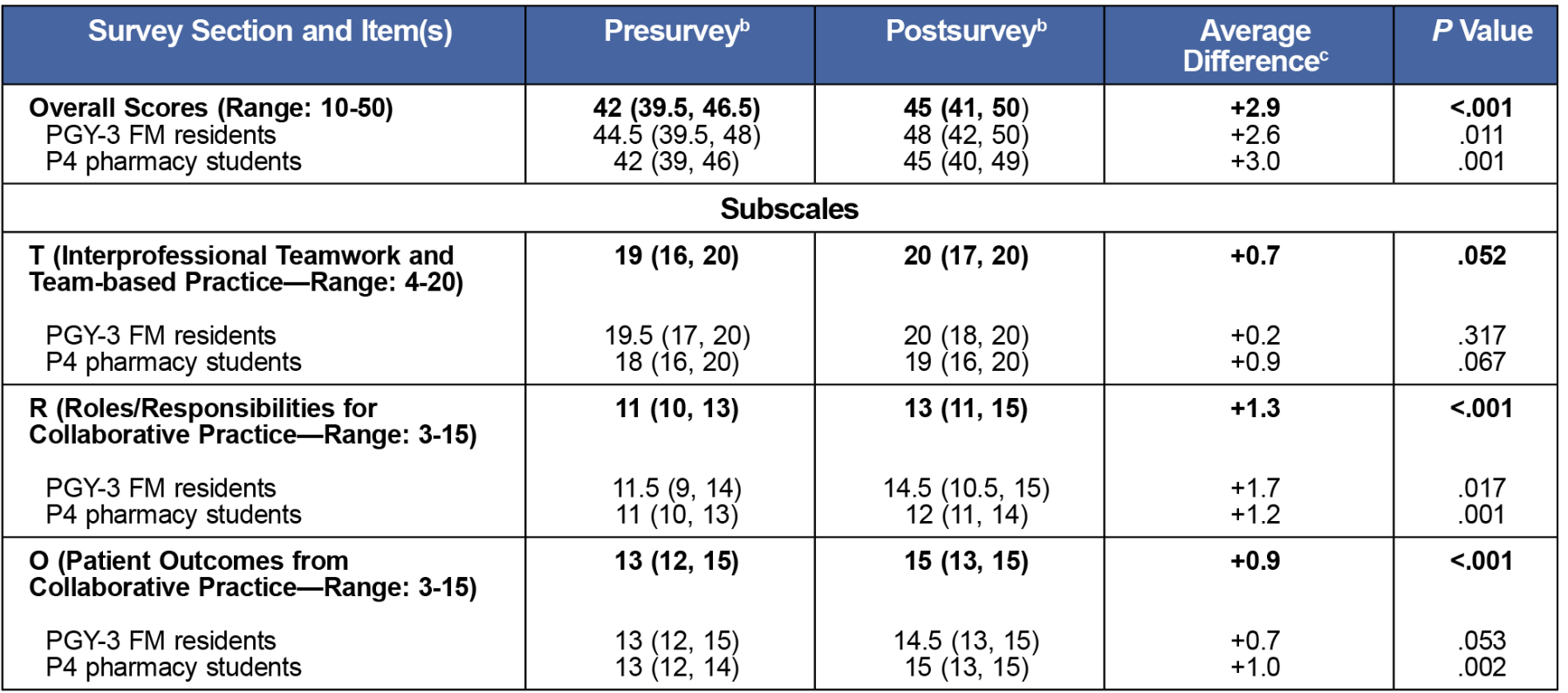

Abbreviation: FM, family medicine.

a $n=10$ for PGY-3 family medicine residents; $n=31$ for $\mathrm{P} 4$ pharmacy students

${ }^{\mathrm{b}}$ Data expressed as median (interquartile range)

${ }^{\mathrm{c}}$ Average difference calculated by subtracting postsurvey summative score minus presurvey summative score and averaging those differences.

Table 3: Results of Skills Perception Postsurvey

\begin{tabular}{|c|c|c|c|}
\hline \multirow[b]{2}{*}{ Survey Question ${ }^{a}$} & \multicolumn{3}{|c|}{ Median (IQR) } \\
\hline & $\begin{array}{l}\text { Overall } \\
(n=41)\end{array}$ & $\begin{array}{c}\text { PGY-3 FM } \\
\text { Resident } \\
(n=10)\end{array}$ & $\begin{array}{c}\text { P4 } \\
\text { Pharmacy } \\
\text { Students } \\
(n=31)\end{array}$ \\
\hline $\begin{array}{l}\text { The debate style activity improved my ability to analyze biostatistical tests and } \\
\text { measures utilized within the studies. }\end{array}$ & $4(3,4)$ & $4(4,5)$ & $4(3,4)$ \\
\hline The debate style activity improved my problem-solving and critical thinking skills. & $5(4,5)$ & $5(4,5)$ & $4(4,5)$ \\
\hline The debate style activity improved my communication skills. & $4(4,5)$ & $5(4,5)$ & $4(3.5,4.5)$ \\
\hline The debate style activity improved my interprofessional teamwork skills. & $4(4,5)$ & $5(4,5)$ & $4(3,5)$ \\
\hline The debate style activity increased my interest in the subject content area. & $4(3,5)$ & $4(4,5)$ & $4(3,5)$ \\
\hline
\end{tabular}

Abbreviation: IQR, interquartile range; FM, family medicine.

a Participants were asked to rate their level of agreement on a scale of 1-strongly disagree, to 5-strongly agree.

\section{Acknowledgments}

Presentations: Interim findings were presented at the following meetings as poster presentations: American Association of Colleges of Pharmacy Annual Meeting, Chicago, IL, July 2019; and American Association of Colleges of Pharmacy Annual Meeting, Boston, MA, July 2018.

\section{Corresponding Author}

Taylor D. Steuber, PharmD, BCPS 
Auburn University Harrison School of Pharmacy, 301 Governors Drive, Huntsville, AL 35801. 256-551-4538. Fax: 256-551-4567

tds0038@auburn.edu

\section{Author Affiliations}

Taylor D. Steuber, PharmD, BCPS - Auburn University Harrison School of Pharmacy, Department of Pharmacy Practice, Huntsville, AL

Miranda R. Andrus, PharmD, BCPS, FCCP - Auburn University Harrison School of Pharmacy, Department of Pharmacy Practice, Huntsville, AL

Bradley M. Wright, PharmD, BCPS, FASHP - Auburn University Harrison School of Pharmacy, Department of Pharmacy Practice, Huntsville, AL

Nancy Blevins, MD - University of Alabama at Birmingham School of Medicine, Department of Family Medicine, Huntsville, AL

Haley M. Phillippe, PharmD, BCPS, BCGP, FASCP - Auburn University Harrison School of Pharmacy, Department of Pharmacy Practice, Huntsville, AL

\section{References}

1. Dy-Boarman EA, Nisly SA, Costello TJ. It's no debate, debates are great. Curr Pharm Teach Learn. 2018;10(1):10-13. doi:10.1016/j.cptl.2017.09.016

2. Ang RX, Chew QH, Sum MY, Sengupta S, Sim K. Systematic review of the use of debates in health professions education - does it work? GMS J Med Educ. 2019;36(4):Doc37.

3. Douglas M. Use of the debate format journal club to teach critical appraisal. Fam Med. 1994;26(7):414.

4. Nguyen VQC, Hirsch MA. Use of a policy debate to teach residents about health care reform. J Grad Med Educ. 2011;3(3):376-378. doi:10.4300/JGME-03-03-32

5. Lieberman SA, Trumble JM, Smith ER. The impact of structured student debates on critical thinking and informatics skills of second-year medical students. Acad Med. 2000;75(10)(suppl):S84-S86. doi:10.1097/00001888-200010001-00027

6. Ong CC, Narasimhan KL. A novel learning experience: case-based, evidence-based debate. Med Educ. 2010;44(5):515-516. doi:10.1111/j.1365-2923.2010.03644.x

7. Koklanaris N, MacKenzie AP, Fino ME, Arslan AA, Seubert DE. Debate preparation/participation: an active, effective learning tool. Teach Learn Med. 2008;20(3):235-238. doi:10.1080/10401330802199534

8. Mamtani M, Scott KR, DeRoos FJ, Conlon LW. Assessing EM patient safety and quality improvement using a novel debate format. West J Emerg Med. 2015;16(6):943-946. doi:10.5811/westjem.2015.9.27269

9. Wahabi HA, Al-Ansary LA. Innovative teaching methods for capacity building in knowledge translation. BMC Med Educ. 2011;11(85):85. doi:10.1186/1472-6920-11-85

10. Mumtaz S, Latif R. Learning through debate during problem-based learning: an active learning strategy. Adv Physiol Educ. 2017;41(3):390-394. doi:10.1152/advan.00157.2016

11. Toor R, Samai K, Wargo R. Debate as an alternative method for medical literature evaluation. Curr Pharm Teach Learn. 2017;9(3):427-432. doi:10.1016/j.cptl.2017.01.009

12. Peasah SK, Marshall LL. The use of debates as an active learning tool in a college of pharmacy healthcare delivery course. Curr Pharm Teach Learn. 2017;9(3):433-440. doi:10.1016/j.cptl.2017.01.012

13. Dy-Boarman EA, Bryant GA, Herring MS, Foster KY. Impact of debates on student perceptions and competency scores in the advanced pharmacy practice setting. Curr Pharm Teach Learn. 2018;10(1):66-71. doi:10.1016/j.cptl.2017.09.011

14. Lin SJ, Crawford SY. An online debate series for first-year pharmacy students. Am J Pharm Educ. 
2007;71(1):12. doi:10.5688/aj710112

15. Bussières JF, Delicourt A, Belaid N, et al. Impact of a debate on pharmacy students' views of online pharmacy practice. Int J Pharm Pract. 2012;20(6):409-412. doi:10.1111/j.2042-7174.2012.00206.x

16. Hanna LA, Barry J, Donnelly R, et al. Using debate to teach pharmacy students about ethical issues. Am J Pharm Educ. 2014;78(3):57. doi:10.5688/ajpe78357

17. Garrett M, Schoener L, Hood L. Debate: a teaching strategy to improve verbal communication and criticalthinking skills. Nurse Educ. 1996;21(4):37-40. doi:10.1097/00006223-199607000-00015

18. Rubin RW, Weyant RJ, Trovato CA. Utilizing debates as an instructional tool for dental students. J Dent Educ. 2008;72(3):282-287. doi:10.1002/j.0022-0337.2008.72.3.tb04494.x

19. Saito A, Fujinami K. Introduction of formal debate into a postgraduate specialty track education programme in periodontics in Japan. Eur J Dent Educ. 2011;15(1):58-62. doi:10.1111/j.1600-0579.2010.00635.x

20. Darby M. Debate: a teaching-learning strategy for developing competence in communication and critical thinking. J Dent Hyg. 2007;81(4):78.

21. Smith Randolph D. Student perceptions of the use of debate as a teaching strategy in the allied health professions. J Allied Health. 2007;36(1):e13-e29.

22. Interprofessional Education Collaborative. Core competencies for interprofessional collaborative practice: 2016 update. https://hsc.unm.edu/ipe/resources/ipec-2016-core-competencies.pdf. Accessed November 2019.

23. Health Professions Accreditors Collaborative. Guidance on developing quality interprofessional education for the health professions. https://healthprofessionsaccreditors.org/wp-content/uploads /2019/02/HPACGuidance02-01-19.pdf. Accessed November 2019.

24. Zorek JA, Fike DS, Eickhoff JC, et al. Refinement and validation of the student perceptions of physicianpharmacist interprofessional clinical education instrument. Am J Pharm Educ. 2016;80(3):47. doi:10.5688/ajpe80347

25. Lockeman KS, Lanning SK, Dow AW, et al. Outcomes of introducing early learners to interprofessional competencies in a classroom setting. Teach Learn Med. 2017;29(4):433-443.

doi:10.1080/10401334.2017.1296361

26. Matulewicz AT, Lanning SK, Lockeman K, et al. Using a mixed methods approach to explore perceptions of early learners in classroom-based interprofessional education experiences. Am J Pharm Educ. 2020;84(5):7693. doi:10.5688/ajpe7693

27. Barker TS, Allen HB, Levitzky EG, Gunaldo TP. Comparison of two dental hygiene student cohorts receiving varying interprofessional and intraprofessional curricula. Health. Interprofessional Practice \& Education. 2020;4(1):eP2116.

28. Gunaldo TP, Augustus-Wallace A, Goumas A, Cheramie T, Brisco S, Levitzky E. Integrating interprofessional education into an academic enrichment program. Health. Interprofessional Practice \& Education. 2018;3(3):eP1132. 